The following is a tabulated summary of the important points of the analyses:

\section{Before the Race.}

1. "Nucleo-slbumen," albumen, globulin and sugar absent in every specimen.

2. Indican present in much excess in one urine. In the other specimens it was present in normal quantities.

3. The sediments, which appeared normal to the naked eye, showed nothing abnormal microscopically except oxalate crystals which were present in five of the eight specimens.

\section{After the Race.}

1. Seven specimens contained "nucleo-albumen" albumen, and globulin, and in the sediments hyalin and faintly-granular casts, and epithelial cells. In three of these there were in the sediments red blood corpuscles; in five calcium oxalate crystals sparsely distributed.

2. One specimen was free from " nucleo-albumen," albumen, and globulin, but contained hyalin and faintly-granular casts in the sediment.

3. Sugar absent in all.

4. The tests for indican gave practically the same results as those before the contest.

\section{INTUSSUSCEPTION OF THE APPENDIX. -BY}

J. W. THOMSON, M.B., C.M., AGSISTANT GURGEON, THE HOSPITAL, WAKEFIELD.

Cases of intussusception of the appendix caeci have been grouped into three varieties by Kelly. In the first of these the presence of the appendix is a mere incident, being compelled to travel with the intussuscepted colon. In the second the base of the appendix forms the apex of the intussusception, and in the third the appendix is completely or partially inverted, like the finger of a glove, "with or without invertion of caecum, colon, or ileum."

The first case I desire to record does not quite corre. spond to any of these, but may, perhaps, be included in the first group:

A. S., aged 6, admitted to hospital December 13th, 1909. Slipped on ice, injuring, apparently slightly, the abdomen. Boon after he began to complain of psin in the abdomen, but continued to attend sohool for a week. The pain was not constant, but occurred in paroxysms, which increased in force and frequency, and was referred to the umbilicus. At home he was trested vigorously with aperients.

I saw him about a week after the onset, and found him suffering severe pain, soresming in sgony. A coil of intestine in active peristalsis conld be seen to the right of the umbilicns transverse in direction. He was sent to Wakefield Hospita with a view to early operation. Next morning, however, the pain had greatly diminished, and within a day or two diseppeared entirely. At this stage nothing could be felt on palpation; there was no rigidity, no tympany, no pain or tenderness. There was no vomiting at any time, no blood and mucus in stools. Rectal examination revealed nothing. Tem perature was always normal. Bowels acted regularly, and arine was normal.

Gradually he returned to ordinary diet and began to get up and at Christmas he had the extras that the season brings, but -no recurrence of pain took place. He was sent home, and the pain returned almost at once.

On readmission the pain quickly subsided, still it was evident that the boy was not thriving, and seemed to be losing weight. On January 25th, 1910, with a tentative diagnosis of appendicular colic, the abdomen was opened by the incision of Battle. The caecum, which was on the level of the umbilicus, could be felt to contain an apparently solid body. The meso-crecum was long, and the caecum was brought into the wound. The base of the appendix was located in its usual position; from this point it passed outwards almost transversely, closely adherent to the caenm in its course for almost 1 it in.; it then took an almost rectangular turn and disappesred into an invagination of the ceecum.

The condition was therefore an invagination of the caecum containing the terminal inch of the appendix. An effort wa made to reduce the intussusception, but ordinary methodsnamely, expression, expression with slight traction-failed.

The caecum was then incised anteriorly and pressure made from within on the congested hard conical, apparently solid intussusception. Gentle effort was of no avail ; less gentle effort merely succeeded in rupturing the caecal wall round the ostium.

The intussusception was then incised, and in it was seen the terminal portion of the appendix olosely adherent to the inner side of the invaginated crecum almost to the tip. The tip was loosely attrohed to the caecal wall. The neighbouring mesenteric glands were enlarged. The caecum was resected Whey milk and water was given from the flrst. Bowels aoted at the end of the second day, and the child got up on the tenth day. The appendix, though not pursuing a straight course, stili seemed tightly stretched from base to apex, and it seemed as if the size of the intussusception was regulated by the length of the appendix.

Was the accident the cause of the condition? A case is recorded in "Kelly and Hurdon" in which a similar injury was supposed to be the cause of a somewhat similar con. dition. Was the presence of the appendix a mere incident in the case? The curved course of the appendix would seem to indicate that the thickening of the caecal wall was the primary condition. "Any inflammatory process in the head of the crecum causing a localized thickening of its walls would offer a convenient grip for the circular muscle of the bowel to catch and exercise propulsive force in the direction of the current " (Kelly and Hurdon). Or was there paralysis of part of the caecal wall from haemorrhage, and hence intussusception (Sutherland) ? The long intervals of freedom from pain or tenderness when taking ordinary diet were remarkable, but still the child was thinner.

Perhaps, at any rate in a somewhat earlier case, a better, and certainly less severe, method of treating such a osse would be to detach the appendix at its base and from the caecal wall outside the invagination. Then incise the caecum in a circular manner round the ostium and remove the invaginated part entire with the contained appendix.

The second case was primarily one of Henoch's purpura in a boy aged 4. He was admitted, April 14th, 1908, with swelling and pain in the knee-joints, and a rash resembling that of chicken-pox and haematuria.

About a fortnight after the onset of the illness severe pain in the sbdomen set in, with stools of blood and mucus. I saw him two days after this, and now vomiting had began, and increased till he could retain nothing. There was slight distension of the abdomen; no definite trmour could be felt, but there wa rigidity of the right side. At the operation was found an in vagination of the caecum, containing the whole of the appendix, the base of the latter forming the apex of the intusausception. It was reduced with ease, and the expressed eppendix stood up rigid and vertical, inviting the extirpation which was its fate. Recovery was uneventful. Albuminuria persisted for six months, but the patient is now in excellent heslth.

Lorenz maintains that intussusceptions in this region begin, not at the ileo.crecal valve, but originate by a rolling in of the caecum itself. In this case the caecum must have rolled in sufficiently to obstruct the ileo-caecal orifice, and is an example of the invaginatio caeco-colica of Lorenz-a potential intussusception of the ordinary variety.

A FRENCH Anthropological Institute has recently been founded in connexion with the Natural History Museum of Paris where there is an anthropological laboratory. The Institute evidently accepts in the fullest sense Pope's dictum that the proper study of mankind is man, and intends to study him in all his aspects. In addition to what may be called anthropologists pure and simple, it is intended that the Institute shall include in its membership palaeontologists, zoloogists, biologists, physiologists, psychologists, linguists, archaeologists, sociologists, geologists, ethnologists, travellers-the list is as long and as varied as that of Don Giovanni's conquests. The President is M. Salomon Reinach; the Secretary-General, M. Lapicque.

THE third International Laryngo-Rhinological Congress Will be held at Berlin this 7ear (Angngt 30th to Septem ber 2nd) under the presidency of Professor Bernhard Fraenkel. The following is the programme of discussions : (1) The relations of experimental phonetics with laryngology ; to be opened with reports from Drs. Gutzmann of Berlin and Struyken of Breda. (2) Bronchoscopy and oesophagoscopy-indications and contraindications; to be introduced by Drs. Killian of Freiburg, Kehler of Vienna, and Chevalier Jackson of Pittsburg, U.S.A. (3) The lymphatic apparatus of the nose and the naso-pharynx in relation to other bodies; to be opened by Drs. Broecksert of Ghent, Poli of Genoa, and Logan Turner of Edinburgh. (4) The so-called naso-pharyngeal fibromata: the site and manner of their attachment and their treatment; to be opened by Drs. Jacques of Nancy and Hellat of St. Petersburg. All communications relative to the congress should be addressed to the secretary, Professor Rosenberg, 26 Schifrbauerdamm, Berlin, N.W. 